\title{
Language and Style of Sunetra Gupta's Fictional Narratives
}

\author{
Maswood Akhter \\ Rajshahi University, Bangladesh \\ maswood2005@gmail.com
}

\section{Abstract}

My aim in this paper is to offer a critical discussion on certain linguistic and stylistic aspects in the fictional pieces by Sunetra Gupta, an important Bengali diaspora author based in Oxford. In her debut novel, 'Memories of Rain' as well as in her others, Gupta effortlessly intersperses prose with poetry; her writing is complex, fusing stream of sensuous poetic imagery with stream of consciousness. A powerful delivery of interior monologue, figurative language, and continuous time-shifts invites the novelist's comparison with Virginia Woolf. Memory becomes a vital player in many of her novels, be it Memories of Rain, Moonlight into Marzipan or So Good in Black. Giving it the centre stage automatically leads her towards an experimental narrative technique, since memory - a highly subjective and elastic category blending fantasy with the past - keeps intervening in the linear flow of the plot. Interestingly, her stream-of-consciousness technique transforms language and punctuation marks from normative linguistic symbols into poignant emotional tools. By exploring the limits of ambiguity in language, as I argue here, Gupta has evolved a personal literary idiom in which prose is pushed into a territory formerly accessible only to poetry. The issue of intertextuality is also discussed, with special reference to Memories of Rain where the influence and interplay of diverse texts provide the novelits context and meaning, and shape its narrative and characters.

Keywords: stream of consciousness, haunting memories, second-person narration, literary language, intertextuality

I consider it pertinent to begin the discussion with how Rabindranath Tagore is integral to the linguistic and stylistic arrangements in Sunetra Gupta's fictional universe. That Tagore had a profound influence on her writing is most evident in her debut novel, Memories of Rain (1992) which won her the prestigious Indian SahityaAkademi Award for 1996: "Memories of Rain is very clearly for me a celebration of my culture, and is recklessly adorned with my own personal translations of a number of Tagore songs that are central to my sensibilities" (Gupta, 2010). Here, as occasionally in her others, Gupta effortlessly intersperses prose with poetry, proving herself to be a creative translator of Tagore's songs and poems. An unmistakable Bengaliness pervades this novel, especially the expression of its female protagonist Moni's anguished passion and "dark" thoughts, articulated through Tagore's songs. 
The writing in Memories of Rain is complex, fusing stream of sensuous poetic imagery with streams of consciousness: a powerful delivery of interior monologue, figurative language, and continuous time-shifts invites the novelist's comparison with Virginia Woolf.

The novel itself, as already indicated, is replete with Gupta's own translations of a number of Tagore's songs, sometimes in both prose and poetry - mostly evoking monsoon but also related to love and puja - used to articulate its central emotions. Tagore's songs provide 'Moni' a magnificent and exaggerated metaphor for her own adolescent pain, romanticism and sexuality. The anguish of the poet shapes the desolation and misery of her own charred passion. And finally it is a Tagore song that echoes one of the core themes of the novel - memories as an autonomous healing-space privileged with the sanctity of forgiveness. Tagore's songs resonate through the subtext of $A$ Sin of Colour (1999) as well, voicing the unspoken angst and desire of Debendranath and Niharika.

If Tagore's songs are one constant through Memories of Rain, the other is a haunting evocation of Calcutta from multiple perspectives - whether it be a glimpse into its cosmopolitan past and present or its nostalgic image as a tired mother betrayed and abused by her own child. Calcutta has been represented from Anthony's superior gaze as well as from Moni's blending of nostalgic imaginings with apparently unbiased vintage footages of the city and its chequered history and geography. Moni's reminiscences create a collage of memories of Calcutta as well as the life and ethos of middle-class Calcuttan Bengalis of the 1970s - struck by both Tagore and communism - and their love for literature, music, theatre, adda and intellectualism. This is possibly Gupta's only novel in which she deigns to furnish intricate anthropological footnotes in order to translate her city to a Western audience. Untranslated Bengali words are sparse in Memories of Rain except the much familiar Bengali word for an elder brother, dada while translated cultural details abound (Akhter, 2011).

There are exhaustive details about Durga Puja - complete with anjali or the offering of flowers to the goddess, and bhasan, the procession carrying the idol of the goddess to the river Ganga - and Kali Puja - the festival of fire - about idols, myths and rituals central to both occasions and the tropical festivity tensed with frantic shoppers. Of course, the "exotic" institution of arranged marriage is not left out, nor are some of the rituals of the elaborate Hindu wedding. The text is replete with another cultural trademark - the Bengali intellectualism and vibrant adda-culture which was almost metonymic of the urban Bengali youth way back in the 1970s. On the other hand, for Moni as for her brother, London was mapped 
by literary coordinates. She had fancied roaming with a Heathcliff-like beloved upon English moors. As Moni leaves, she remembers walking "upon the very streets that Dickens, Hardy, Virginia Woolf had trod" (Gupta, 1992, p.148); the actual geographical points of Tottenham Court Road, Gower Street or University College Hospital become more like a dream. Her emotional geography of London cluttered by Big Ben and literary personae, sites and myths do not correspond to the aloof and uncaring city where she finally feels strangely trapped.

Memories of Rain, in a way, is an elegy for Bengali culture and for the genre of romance. Apparently it is about a middle-class Bengali romantic dream come true - a young sensitive girl married to and carried off across the seven seas by the white prince of her dreams. The novel is a rather anti-romantic sequel to the last line of this fairy-tale - "And they lived happily ever after." The favourite fantasy translated into reality spells trauma for the girl, since the prince neither cares for nor respects her; the medieval genre of romance and its myth of true love become a weird joke in the context of Moni and her promiscuous husband. Moni's return is ironically paralleled with Goddess Durga's mythic annual visit to this earth, her father's home, which is the occasion of Durga Puja in Bengal; she has accidentally timed her ticket on the eve of the Puja. Her return, however, is laced with bitterness and humiliation and she might not be as welcome back home as Devi Durga is. Whilst Moni is apprehensive about the possibility of rejection by her maternal city, her return to Calcutta is nevertheless rendered in mythical terms and enshrined by the ritualistic Durga Puja ceremony, a ceremony which enacts a welcome for the Goddess to her father's home (Ganguly, 1996).The mythic parallel pre-empts a healing possibility of the unconditional acceptance of a daughter come home, in spite of all humiliation and pain.But in the end, she too does manage to transform a traditional tale of woman's victimhood and retaliation - the myth embodied in Euripides' Medea - into one of agency without bitterness.

Memories become the redemptive gesture in this novel; they create the healing-space where nostalgia and compassion become possible; unfocused and uncensored memories provide Moni with moments of pure rebellion as well. On the eve of her departure, she floods Anthony and Anna with her hysterical "torrent of anecdotes" (Gupta, 1992, p.123) based on memories of Calcutta. In the process, she usurps her friends' stories as well, since she wants to reconstruct the Calcutta of the 1970s for these foreigners through a collage of private memoirs. It provides her a cathartic domain where she can fully inhabit her culture without inhibition or embarrassment and flaunt her resistance to integration into the British cultural mainstream. She regales them on that eve 
with literal translations of Bengali proverbs e.g. "picked snake gourd" meaning "died" or "moon of a moonless night" meaning "someone we do not see very often." Memories of these proverbs or of funny local superstitions - e.g. with the rats' blessing, children could have sharp rodent teeth sprouting once their milk teeth fell (p.154) - release her from the pain of a long-sustained suppressive elegant silence. Moni has again and again caught Anthony drifting away from her, locked in his own memories. Ironically, memories - personal as well as cultural - bind, as well as set us free; Moni, for example, is freed of her bitterness for Anthony and London by remembering her togetherness with both. Even as she leaves London, she carries the city with her in a series of nostalgic images "watercress in the window, wild heath pond fringed by luminous rushes, ducks, foul geese among the violent yellow of new daffodils, the woman upon Oxford Street crushing ice cream cones to feed the pigeons" (p.172). And the novel ends with memory as the only viable idiom connecting Anthony and Moni. It finally becomes the elusive amniotic sap that could salvage the being. As implied in the title, the text builds itself as a self-reflexive house of memories - of persons, moments, cities and a culture - promising thereby both author and reader the jouissance, peace and nest that had escaped the questers within the novel, Anthony and Moni.

Memories of Rain, however, in its lyrical evocation of Calcutta and its haunting memories, its warped chronology alternating flashbacks and fantasy with the present, its paragraph-stretched sentences conjoined by commas and overflowing grammatical halts, has been a less experimental venture than her next fiction, The Glassblower's Breath (1993) where Gupta moves closer to her theorising about home and diaspora, exemplified by the novel's transnational characters seeking the healing-space of home in the very condition of being unhoused. The Glassblower's Breath has something of the quality of myth; her narrator, like T. S. Eliot's Tiresias, floats freely through every character's mind. Moreover, here, as in Gupta's other works, even the quotidian gets imbued with a melancholic mysticism. The protagonistdoesnot have a name and is addressed throughoutby the second person pronoun "you," maybe because, her identity can never be fully grasped.As in a house full of mirrors, her image is viewed through different perspectives, none of which is satisfactory or permanent. All the dislocations of life are articulated in this novel by multiple male narrators who trace the adventure of the female protagonist; the reader has to reconstruct her personality by stitching together these shards of narration. The possibility of authentic knowledge about the self is lost, as lost as the possibility of returning home. 
The Glassblower's Breath, as I have already indicated, has a more unconventional style than Memories of Rain: the second-person narration, multiple perspectives about the protagonist, re-vision of the idyllic notion of home and a greater relish for the absurd. Many of the events in this book border on the surreal, such as Jonathan Sparrow's encounter with an eccentric aesthete who believes he has arrived to assist him in preparing a full alphabetical dinner. The referent of you, the unnamed female protagonist, remains constant throughout the text, whereas the focalisation changes constantly, either rendering the 'you'-protagonist's point-of-view or the perspectives of the four men enamored of her. There are also sections of "ordinary" third-person narrative with internal focalisation on Rima, the niece (Fludernik, 1998, p.279).

Now, the accent on individual politics and mental adroitness - which was explored through the lens of nostalgia and diaspora in her first two novels becomes conspicuous in her characteristically lyrical third novel Moonlight into Marzipan (1995). This is a story of marriage and betrayal: Promothesh and Esha, dreamy youngscientists who were classmates at Calcutta University, find their relationship changing after marriage. The title of this novel once again reveals Gupta's liking for poetic and at times oblique titles for her work; the title here refers to the process of photosynthesis - the means by which light is parceled into usable energy by plants. Promothesh makes an accidental discovery about this fundamental process which promises fame and riches. Instead, it triggers a chain of events that begins with his arrival in London and ends with his infidelity and Esha's suicide; the astonishing discovery too is forgotten in the process. Into this morass of ambition and self-pity slip love in the form of his biographer Alexandra Vorobyova and the devil himself, in the form of Yuri Sen, also a Bengali researcher. Yuri Sen subverts the narrative by using italics and telling readers that Promothesh is incapable of writing to them. The blasphemous dream of creating paradise on earth and of articulating the secret of life turns into an interminable experience of hell (Ponzanesi, 1997).

Moonlight into Marzipan has no reliable narrator, and from the opening pages, the reader has to struggle in order to locate the central characters and identify the perspectives from which they are viewed. When Alexandra goes away and abandons the text, Promothesh is left only with shreds of his life scribbled down in notes - the results of his long conversation and confessions with the dismissive narrator. The novel takes the form of a dialogue between Promothesh and the absent narrator, playing with the ambiguity and confusion between the subject and the object of narration. Personal pronouns "I" and "you" are peppered into the text in the attempt to reconstruct the trajectory of Promothesh's life, a 
project that remains unfulfilled in the text. There are constant shifts backward and forward in time and space, leaving the task of re-assembling the fragments of various overlapping and incomplete texts to the reader. In Moonlight into Marzipan too, as in the previous novel The Glassblower's Breath, characters are not representatives of a particular space or culture, but of human vulnerability, estrangement and appropriation of narration which cut across geographical boundaries and anthropological curiosity. The initial self-consciousness and the desire to present Bengal are now over. As she tells in a 1996 interview: "My work is more 'free' now."

Gupta's fourth novel, $A$ Sin of Colour is about the choices made by its two protagonists, Debendranath Roy and his niece Niharika, when both are in the last phase of youth, during two different time periods. The narrative sprawls across Oxford and the United States, Calcutta and the rural Bengal, but most of the action takes place in Oxford and Calcutta, the twin geographies close to Gupta. Both characters are victims of unrequited love which colors their lives profoundly, eventually leading them to their sins (Gupta, 2011). Through seven sections named after seven colors, starting with "Amethyst" and then moving through "Indigo," "Azure," "Jade," "Saffron," "Ochre" and "Crimson", Gupta tells the story of three generations of a house in Calcutta called Mandalay. Built by a British officer, it passes into the hands of the wealthy Roy family. The multiple sins, each associated with a color, are all fuelled by obsessional love and concern the one sin that forms the basis of this book - Debendranath's retirement from this world; his desire for a life uncluttered by lies by running away from all ties makes the story take a curious turn when a man in his late thirties is last seen entering a punt on the Cherwell in Oxford. When he can no longer be traced, Debendranath Roy is presumed drowned. He leaves behind a pale and languishing widow in Oxford and a mystery that takes twenty years to unfold.It turns out that Debendranath had fled back to India where he had lived incognito; his growing blindness drives him back to the family and to his writer-niece Niharika, who is almost the only family member living in Mandalay.

The thinness of the plot, evident from the above summary of $A$ Sin of Color is also noticeable in Gupta's first novel Memories of Rain, but in both these novels this thinness is brilliantly obscured by Gupta's virtuosity with literary language.Again, A Sin of Color, too, eludes chronology or the expectations from a linear story; the narrative unfolds like a conversation - picking one thread and jumping back and forth into the past - with repetitions becoming an inviting story-telling tool.

Gupta comes up with her fifth novel, So Good in Black (2009) after almost 
a decade of absence. Here too the characters are transnational and the geographies fluid, with a narrative featuring multiple registers and perspectives of myriad characters. Max Gate, an American travel-writer and his once beloved friend Byron Mallick, a charming and refined Bengali businessman, meet again in extraordinary circumstances on the shores of Bengal. It is the eve of transit of Venus in 2004 - a day astrologically associated with transformation of consciousness. Byron is facing charges of murdering a crusading journalist Damini whose cousin Ela haunts Max years after their affair has ended. Ela is caught between her deep attachment to Byron, her loyalty to her husband and her desperate love for Max. Meanwhile Max's former brother-in-law, Piers O'Reilly, is determined to bring Byron to justice. As the intricately layered tale unfolds, all certitudes about love, friendship and morality dissolve into tantalising ambiguity, defying easy resolution. As a critic says, "Sunetra Gupta's latest novel So Good in Black is a richly layered narrative of moral and emotional dislocation across time and space, which dissolves all notions of static truths" (Padmanabhan, 2005). At the end, as many of the central characters orbit around the enigmatic Byron Mallick, only the redemptive power of memory seems able to heal the scars of loss and betrayal.

Memory, thus, becomes a vital player in many of her novels, be it Memories of Rain, Moonlight into Marzipan or So Good in Black. Giving it the centre stage, however, could demand an experimental narrative technique, since memory a highly subjective and elastic category blending fantasy with the past - keeps intervening in the linear flow of the plot. This is particularly so in the novels of Sunetra Gupta in which thin plots are resolved by or revolve around momentous events like deaths, disappearances, drowning and suicides. She even defies the need of a story in order to weave a fiction: "The notion that a good story is crucial to good fiction seems very confining, as if there is a quality control checklist on commodities that works of art must meet" (Padmanabhan, 2005).

Importantly, Gupta's stream-of-consciousness technique transforms language and punctuation marks from normative linguistic symbols into poignant emotional tools. By exploring the limits of ambiguity in language, she has evolved a personal literary idiom in which prose is pushed into a territory formerly accessible only to poetry: "There is not enough of a space between poetry and prose and what I do. The novel swallows everything I do" (Nagy, 2009).The author discourses on her style and attitude to language and punctuation in several interviews and essays, as well as in a debate between two of her erudite characters, Jonathan Sparrow and "you," in The Glassblower's Breath: 
He(Sparrow) snorted...Vowels are the essence of unambiguity, which I despise, vowels are the poor props of thin narrative, vowels emaciate the language, as do punctuation marks, paragraphs, and all other instruments of linguistic torture.

Why has man struggled to give definition to language, saddle the infinity between consonants with the cruel measure of vowel, why, when all else has been an obsession with the inconcrete, why chisel language when poetry must remain undefinable...language has been dragged into the arid plain of concrete communication, once poetry was language, when the unspoken chasms between the consonants were replete with dream, as now only the hollows between words and images may be...(pp.132-33).

Gupta's sentence construction deviates from the classical grammatical sentence in English. Her long sentences, some going on for almost a page, are filled with adjectives, descriptions and double metaphors, and they meander through different thought processes, coming to a halt abruptly when she seems to have run out of breath. The dialogues are all without quotes and blend into the general narrative. Examples abound in Memories of Rain. Unlike the protagonist Moni in this novel who is a cautious, even reverent, user of the coloniser's tongue, Gupta forges her own variant of English as a signifier of power. As she comments in her essay "Avoiding Ambiguity" (2001): "in several post-imperialist cultures ... its very flexibility sometimes permits English to escape the fate of oppressor's language by mutating into a poetic hybrid, as in some examples of post-colonial literature."

Gupta's English reads like a translation of stylised, even poetic Bengali, in a perhaps unconscious continuum with many other Indian writers in English. Gupta justifies (2001) the poetic meandering of language and stylistic innovation by vouching for ambiguity in literature, a passion she shares with her character Sparrow: "In literature, it is often ambiguity itself that enriches our understanding of the human condition. ... Much of the potential energy of literature lies unlocked in the gap between word and referent. This plasticity of meaning is still exploited quite explicitly in poetry... Prose, however, appears these days to come under a different jurisdiction." She further reflects, "I was happily not aware of this when I sat down, more than fifteen years ago to write my first novel-Memories of Rain. I had no preconceived desire to play with words or sentence-structure, but what emerged was English that was largely devoid of fullstops, and where clauses often belonged to both its flanking sides ..." (Gupta, 2001).

Gupta's reaction (2005) to punctuation, according to her own understanding, is "truly visceral," and she "physically abhor[s] the repeated use of the full-stop." 
She explains, "There is something too final about the full-stop - I am happy to use it judiciously, but mostly I rely on commas to separate interlinked ideas. Conversely, sometimes, the finality of a full-stop is not enough, and I need to employ paragraphs or even blank lines or a row of asterisks to create the correct pause between sections of prose." Gupta finally believes that "It is natural that a writer's relationship with his punctuation should be emotional" (Gupta, 2005).

Gupta dislikes the traditional precise sentence with its unambiguity and precision: the sentence, as she maintains in "Avoiding Ambiguity," evolved from the needs of logic and law, but these are not the priorities in fashioning her style. She culls canonical support for emotional revision/s of the conventional usage of punctuation and the sentence:

I am writing a book on contrasting narratives in literature and science, gathering examples of visceral responses to punctuation. Arvind Krishna Mehrotra says the semicolon A.K. Ramanujan uses in his sentence acts as an osmotic membrane between the two languages and realities he inhabits.... As for my writing, reaching a point in a sentence which would naturally beg a full stop I would feel reluctant, thinking of a comma or dash.

It's about finding a style consistent with how I am feeling. When writing something, I see it as having its own cadence, form, and try and recruit punctuation to create, re-create that (Padmanabhan, 2005).

Gupta, however, insists that she has never consciously adopted a particular style, and it was never part of her project to reject conventional grammar. Importantly, her reluctance to use full stops has to do, among other things, with her Bengali sensibility, as she explains: "Because in Bengali a full stop is represented by a vertical line and that has a more organic relationship with the rest of the letters. In English, this bullet thing is intrusive to my own construction" (Nagy, 2009). Bengaliness in Gupta's writing is not a carefully constructed identity that finds reassurance in difference with others but rather a function of her poetic self that is formed out of diverse, often contradictory, influences deriving from place, history and culture. The many references to monsoons and her evocative suggestions of the appeal of the long wet months are also indications of her distinct style.

I seek to wind up the present discussion by raising the issue of intertextuality in Gupta's fiction. Gupta's style, especially her stream of consciousness technique, textual experiments regarding punctuation and sentence-construction and her female protagonists - has earned her repeated comparisons with Virginia Woolf. 
Gupta herself cites the canon - though of Indian poetry in English - in order to justify her linguistic innovations. Woolf is not the only canonical shadow lurking through Memories of Rain; the novel is rather full of intertexts - cinematic and literary - jostling with each other. The canonical link runs deeper: there are at least two classic texts used as metaphor or pre-texts to this novel. One of them has been openly acknowledged - it is a contemporary revision in the Irish context of the Greek tragedy, Euripides' Medea (Gupta, 2010).The other has only been subtly owned. It is a classic Bengali text, Maitreyi Devi's Na Hanyate about a young Bengali woman who has moulded herself according to Tagore's ideals of womanhood, idolises the poet and has a tumultuous but tragic love-affair with a white student of her father, MirceaEliade.

Not only does Memories of Rain explore the influence of Rabindranath Tagore on the Bengali psyche, but it takes as prequel the text Na Hanyate, a more idyllic version of some of the favourite Bengali obsessions - for example, the old manic Anglophilia, the pervasive presence of Tagore beinga continuous leitmotif. Both Memories of Rain and $\mathrm{Na}$ Hanyatethus engage with image-clusters vital to the life and ethos of the middle-class Calcuttan Bengali. If Medea and Na Hanyate are the two major co-texts of this novel, then innumerable references to intertexts in multiple languages are sprinkled throughout. Wuthering Heights has shaped Moni's notion of doomed and passionate, though naively pure, love: "She had loved Heathcliff before she loved any man ..." (Gupta, 1992, p.177).

Moni's sensibility, influenced greatly by the canon of English literature as represented in the Calcutta University undergraduate syllabus, learns to languish for surrender and death. John Keats is an oft-quoted poet in this novel; his "Ode to Melancholy" frames the dark evening of her first encounter with Anthony in monsoon-ravaged Calcutta. British texts have helped her map the sacred geography of London, the imaginary homeland of many cultured Bengalis' intellectualism and acquired literary taste. That is how Moni could visualise the "chalk cliffs of Shakespeare's demi-paradise" (p.157) Wessex or Bristol where Rammohan Roy lay buried, long before she had geographically visited these sites. When she was twelve she had fed upon the romanticism of Bankim Chandra Chatterjee's novels deeply influenced by Victorian fiction. As newly-wed Anthony caresses Moni's dark hair in tender ecstasy, she remembers Jibanananda Das's "untranslatable line" from the poem "Banalata Sen": "And her hair is a long-lost night of the ancient kingdom of Bidisha" (p.159); and as he makes furious love with his lust for Anna in mind - to her, she can only compare the distant moon to Sukanta Bhattacharya's notoriously anti-romantic image of "charred bread in the eyes of the hungry" (p.89). 
Archetypal myths from the epic Mahabharata - e.g. that of Satyabati the ferrywoman who got rid of the strong odour of fish that clung to her since birth and emerged lotus-fragrant from her illicit love with sage Parashar (p.162) - haunt Moni, as she looks at Anna who is flushed with love for her husband. The estranged couple's emotions are in the end connected through T.S. Eliot's "Marina"; Anthony remembers identical lines from the poem in order to capture the well of emotion within himself when his daughter is born, which Moni ironically does after six years to bask in his imagined pain on losing the child. The sahib is teasingly compared by her brother to one of those disheveled lovelorn alcoholic heroes of Sarat Chandra Chatterjee like Devdas. This further kindles Moni's passion, for she always expected her lover to emerge out of a book. Finally, more than Heathcliff, it was perhaps Tagore's couplet on fated love in his novel Chaturanga (Four Quartets) that pushed Moni to take the leap, to surrender to Anthony's fevered passion perfumed with potential disaster: "In the dying light of that March day/I saw in your eyes, my doom" (p. 25). Tagore is, literally, the major context and co-text of this novel.

Canonical texts and historical and cultural icons echo in her other novels as well -Moonlight into Marzipan is inspired by Oedipus and The Great Gatsby, So Good in Black by historical accounts of the trial of Warren Hastings and $A$ Sin of Color by Rebecca and the whispered rumour of the incest between Rabindranath Tagore and his sister-in-law. Besides, these textsfrom Gupta also abound in intertextual references. In A Sin of Color, for example, Niharika's friend and aspiring suitor Rahul stages a Bengali version of the play "The Threepenny Opera" and Daniel Faradey whistles the theme of the play as Niharika finds him waiting for her after a gap of six long years. Again Niharika's mother, the beautiful and aloof Reba plays Medea - "a woman stunned beyond reason by the failure of love" (Gupta, 1999, p.161). In The Glassblower's Breath, too, "you" enjoys reading Anna Karenina and remembers her conversation with John Sparrow on Rilke's Duino Elegies.

Gupta's fiction is thus immersed in conversation with the expanse of literature produced in different periods and diverse cultural settings: her extremely literary- even canonical- sensibility is revealed in the centrality and profusion of allusions and references that range from Euripides to Tagore. For a more nuanced understanding of her novels, it is, therefore, important to be aware of the influence and interplay of diverse texts providing the novels their context and meaning, and shaping their narratives and characters. The overwhelming canonical shadows lurking through the texts, their eclectic range of allusions and literary inspirations, need not, however, be construed as any conscious attempt on the part of the author at cultural integration, or at offering any thesis attesting the universality of human experience recorded in literatures irrespective of age 
and culture; it is rather, while revealing Gupta's extremely literarysensibility, mostly functional instead of theoretical. Much of the development of the narrative significantly depends upon the intertextuality, their convergence with and deviation from the shadow of those intertexts (Akhter, 2015).

\section{References}

Akhter, M. (2011). Sunetra Gupta's memories of Calcutta and Tagore. South Asian Review, 32 (2), 85-112.

Akhter, M. (2015). Texts within text: The shaping of Sunetra Gupta's Memories of Rain. Asiatic (Humanities), 60 (1), 17-34.

Fludernik, M. (1998). Colonial vs. cosmopolitan hybridity: A comparison of Mulk Raj Anand and R K Narayan with recent British and North American expatriate writing (Singh-Baldwin, Divakaruni, Sunetra Gupta). In M. Fludernik (Ed.), Hybridity and post colonialism: Twentieth century Indian literature (pp. 261-90). Tubingen, Germany: Stauffenburg.

Ganguly, D. (1996). Of dreams, digression and dislocations: The surreal fiction of Sunetra Gupta. In Vinay Kirpal (Ed.), The postmodern Indian English novel. Mumbai, India: Allied Publishers.

Gupta, S. (1992). Memories of rain. New Delhi: Penguin.

Gupta, S. (1993). The glassblower's breath. London: Orion.

Gupta, S. (1995). Moonlight into marzipan. New Delhi: Penguin.

Gupta, S. (1996). A readership is being created by offering them exotic tidbits to titillate them. Retrieved from http://www.rediff.com/news/Feb/21women.htm

Gupta, S. (1999). A sin of colour. New Delhi: Penguin.

Gupta, S. (2001). Avoiding ambiguity. Sunetra Gupta Homepage. Retrieved from <http:// www.sunetragupta.com/essays2.asp

Gupta, S. (2005). The relationship between language and thought. Retrieved from http://www. sunetragupta.com/essays/the relation between language and thought.htm

Gupta, S. (2009). So good in black. New Delhi: Women Unlimited.

Gupta, S. (2010, January 25). Memories of rain.Sunetra Gupta's Homepage. Retrieved from http://www.sunetragupta/Memories of Rain.asp

Gupta, S. (2011, January 5). A sin of colour. Sunetra Gupta Homepage.Retrieved fromhttp:// www.sunetragupta.com/asinofcolour.asp

Nagy, K. The Elements of Style. (2009, May 20). Sunetra Gupta's homepage. Retrieved 
from http://www. sunetragupta.com/reviews and interviews. asp

Padmanabhan, C. (2005, April 5). Of lost moorings. The Hindu Online. Retrieved from http://www.thehindu.com/mag/2009/04/05/stories/2009040550030200.htm

Ponzanesi, S. (1997). Voyage to hell: Sunetra Gupta's Moonlight into Marzipan. Wasafiri 26, 73-75. 